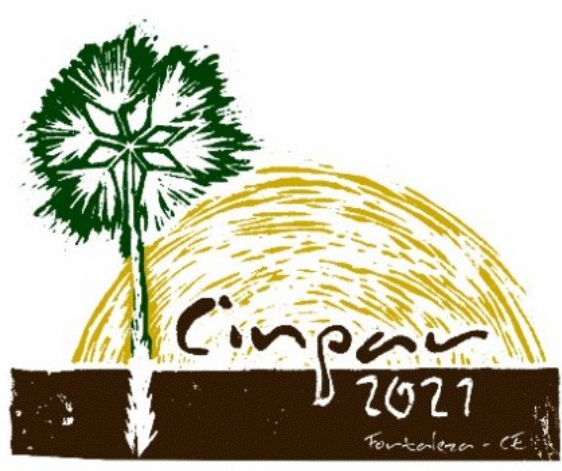

XVII Congresso Internacional sobre Patologia e Reabilitação das Construções

XVII Congreso Internacional sobre Patología y Rehabilitación de las Construcciones

XVII International Conference on Pathology and Constructions Rehabilitation

FORTALEZA (Brasil), 3 a 5 de junho de 2021 https://doi.org/10.4322/CINPAR.2021.147

\title{
Relação entre os defeitos comuns em sistemas de revestimento em argamassa e as zonas constituintes das fachadas
}

\section{Relationship between common defects in mortar coating systems and as constituent areas of facades}

\author{
Hiago Gomes PEREIRA ${ }^{1}$, Jessica Siqueira de SOUZA ${ }^{2}$, Alan Ribeiro SANTOS ${ }^{3}$ \\ ${ }^{1}$ Universidade de Brasília, Brasília, Brasil, hiagopgomes@gmail.com \\ ${ }^{2}$ Universidade de Brasília, Brasília, Brasil,jss.siqueira@gmail.com \\ ${ }^{3}$ Universidade de Brasília, Brasília, Brasil, alanrsmbs@gmail.com
}

\begin{abstract}
Resumo: Os sistemas de revestimento de fachadas de edifícios são coberturas aplicadas nas superfícies externas de edifícios que podem se apresentar em forma de pintura, argamassa ou peças cerâmicas. A proteção contra os agentes de degradação da alvenaria e dos elementos estruturais revestidos é promovida pelo sistema de revestimento. Além da função de proteção, este sistema possui funções estéticas, de impermeabilização e termo acústicas. Entretanto, é comum o surgimento de defeitos nos sistemas de revestimento de fachadas prejudicando estas funções. $O$ estudo dos defeitos permite estimar o atendimento destas funções, e consequentemente a vida útil do sistema de vedação externa do edifício. A partir da análise dos sistemas de revestimento de fachadas, este estudo visa relacionar os principais defeitos em sistemas de revestimento em argamassa com as áreas em que surgiram estes defeitos. Esta análise fornece informações aos responsáveis pelos projetos e processos de executivos quanto a critérios e cuidados a serem considerados na elaboração e execução de sistemas de vedação externa de edifícios revestidos por argamassa.
\end{abstract}

Palavras-chave: Argamassa, Revestimento, Defeitos comuns

\begin{abstract}
Building facade coating systems are coverings applied to the exterior surfaces of buildings that can be in the form of paint, mortar or ceramic tiles. Protection against the degradation agents of masonry and coated structural elements is promoted by the coating system. In addition to the protection function, this system has aesthetic, waterproofing and thermo-acoustic functions. However, faults in façade cladding systems are common, impairing these functions. The study of defects makes it possible to estimate the fulfillment of these functions, and consequently the service life of the building's external sealing system. Based on the analysis of façade coating systems, this study aims to relate the main defects in mortar cladding systems with the areas in which these defects arose. This analysis provides information to those responsible for projects and executive processes regarding criteria and precautions to be considered in the design and execution of external sealing systems for buildings covered with mortar.
\end{abstract}

Keywords: Mortar, Coating, Common Defects

\section{Introdução}

As superfícies externas de edifícios são denominadas como sistemas de revestimento de fachadas. Estes sistemas podem se apresentar como em forma de pintura, argamassa ou peças cerâmicas. 
A proteção contra agentes externos, tal como chuva, ventos e variações de temperatura, é uma das funções exercida pelo sistema de revestimento. Além da função de proteção, este sistema deve promover impermeabilização e atender alguns critérios termoacústicos e estéticos. Existem diversos sistemas de revestimento de fachadas, os quais são compostos por diferentes materiais que influenciam de forma significativa na durabilidade, manutenibilidade, custo, conforto térmico e acústico. Os defeitos comuns em fachadas são características a cada sistema de revestimento de fachada, devido ao comportamento diferenciado do sistema. Na região centro oeste do Brasil, o sistema de vedação vertical comumente empregado é composto por alvenaria com revestimento cerâmico ou em argamassa, com ou sem acabamento em tinta (Amorim e Flores, 2005; Braga e Amorim, 2004). Comumente, o sistema de revestimento em argamassa (Figura 1) possui duas camadas: chapisco aplicado diretamente sobre a base, e a argamassa de reboco que consiste no acabamento final e regulariza a superfície.

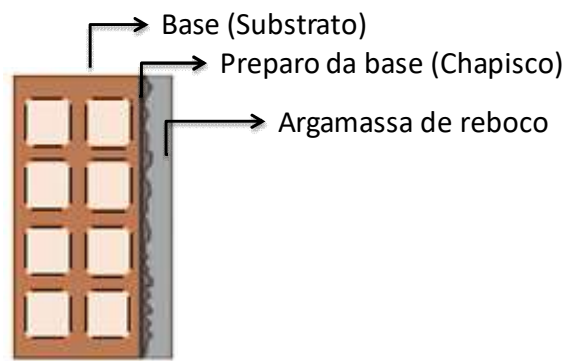

Figura 1 - Sistema de revestimento em argamassa

A ocorrência de defeitos em sistemas de revestimentos em argamassa está associada a qualidade intrínseca dos materiais utilizados, a dificuldade de se estabelecer uma execução adequada. Muitas vezes o surgimento dos defeitos não é causado por apenas uma causa, e sim pela combinação de fatores (Shohet et al., 1999; Hovde e Moser, 2004). A patologia do sistema de revestimento consiste no estudo dos sintomas, mecanismos, origem e causa dos defeitos (Sousa et al., 2016; Pereira et al., 2020). A grande parte da mão de obra no setor brasileiro de engenharia civil não é devidamente treinada a aplicação de revestimentos, incluindo desde engenheiros, fabricantes a aplicadores que ocasionalmente conduzem o processo de revestimento para aquém do ideal. Desta forma, conforme Verçoza (1991), a origem da maioria dos defeitos ocorre nas etapas de projeto e execução da construção do edifício. Os efeitos de atuação de agentes externos e climatológicos são acelerados em condições inadequadas de aplicação de sistemas de revestimentos em argamassa (Medeiros e Sabatini, 1999).

A compreensão dos principais defeitos em sistemas de revestimento em argamassa pode auxiliar na condução de melhores práticas no ambiente de construção civil, levando a processos construtivos mais eficientes e duráveis. O objetivo desta pesquisa é compreender e relacionar os defeitos comuns em sistemas de revestimento em argamassa nas zonas constituintes da fachada de edifícios. Para tanto, com base na literatura, foi obtido o índice de relação das zonas e dos defeitos por meios de matrizes de correlação.

\section{Defeitos em sistemas de revestimento em argamassa}

Os defeitos em sistemas de revestimento em argamassa podem prejudicar tanto aspectos estéticos quanto aspectos funcionais do sistema. Dentre os diversos defeitos listados por pesquisadores (Verçoza, 1991; Sousa et al., 2006) destaca-se como as principais as fissuras, manchas, mofo, descolamento e vesículas. A Figura 2 ilustra os principais defeitos em revestimentos de argamassa.

a.

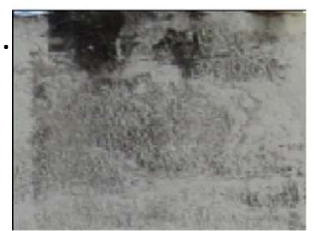

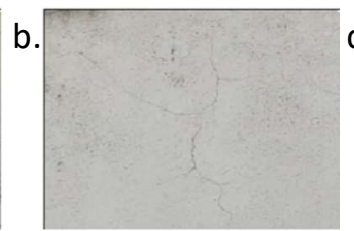
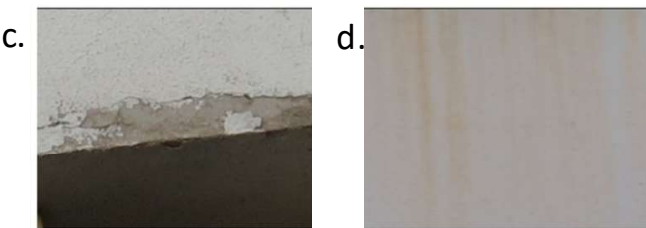

e.

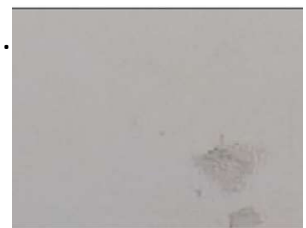


Figura 2 - Defeitos comuns em sistema de revestimento em argamassa: Mofo (a); Fissuras (b); Descolamento (c); Manchas (d) e; Vesículas (e)

As manchas de umidade correspondem ao mofo ou bolor. Esse defeito é uma alteração observável macroscopicamente na superfície dos materiais, sendo uma consequência do desenvolvimento de microrganismos pertencentes ao grupo de fungos. A decomposição dos revestimentos é promovida através da secreção de enzimas que quebram moléculas orgânicas complexas até compostos mais simples, que são assimilados e utilizados no seu desenvolvimento (Alucci et al., 1998). A principal causa destes defeitos está associada a condições ambientais, sendo a umidade o principal fator para o seu desenvolvimento.

As fissuras são caracterizadas por interrupções, lacunas, nos sistemas. Estas geralmente ocorrem devido a deformações induzidas, diretamente ou indiretamente, por esforços de tração (Fiorito 2010; Uchôa, 2015). Nas argamassas de revestimento, sem que haja movimentação ou fissuração de base (estrutura de concreto ou alvenaria), a incidência de fissuras geralmente está condicionada a fatores relativos à execução do revestimento argamassado, solicitações higrotérmicas, e principalmente por retração hidráulica da argamassa (Bauer et al., 2015).

O descolamento pode ser identificado visualmente, pois este é caracterizado pelo desprendimento do material do sistema. Geralmente, este defeito possui como causa falha da aplicação da argamassa e emprego de materiais não adequados a realidade da obra (Leal, 2002). Ou quando a execução é realizada adequadamente, este defeito surge devido à estabilidade rígida do material constituinte, não resistindo a esforços de flexão, tração ou torção ocasionados pela movimentação do sistema de vedação ou da estrutura do edifício (Santos et al., 2017).

As manchas podem surgir de diversas formas, pois estas podem ser manchas de corrosão, manchas de eflorescência, por contaminação atmosférica, entre outras. As manchas de eflorescência são provenientes do processo de lixiviação de sais de materiais alcalinos (sódio e potássio) e alcalino-terrosos (cálcio e magnésio) que são solúveis ou parcialmente solúveis em água. A água que atua nesse processo pode ser proveniente da chuva ou até mesmo do solo onde, ao dissolver os sais, essa solução migra para uma superfície e, após a evaporação, forma-se um depósito de sais, formando manchas esbranquiçadas (Uliana et al., 2014).O surgimento de eflorescência ocorre quando há a coexistência de três condições: presença de umidade, presença de sais solúveis nos materiais e condições ambientais que permitem o fluxo de água (Flores-Colen et al.,2004). As manchas provocadas por contaminação atmosféricas envolvem a absorção de partículas estranhas ao revestimento de argamassa (Segat, 2005; Barros e Moura, 2017). O pó, fuligem e outras partículas contaminantes existentes em suspensão na atmosfera, podem recobrir os revestimentos externos das edificações. As manchas por sujeira ocorrem devido à poluição atmosférica, esta, por sua vez, contém partículas em suspenção formadas por $\mathrm{SO}_{2}, \mathrm{H}_{2} \mathrm{~S}, \mathrm{NH}_{3}, \mathrm{SO}_{4}$, que podem se depositar por ação eletrostática na superfície da fachada, e ao ser carreadas pelo fluxo d'agua, criam diferenciações de tonalidades na superfície da fachada. A mancha por corrosão é, segundo Santos et al., (2017), decorrente do transporte pela água de produtos de corrosão de elementos metálicos (óxidos), provindos de armaduras expostas, esquadrias, peças metálicas de fixação e outros elementos metálicos presentes na fachada.

As vesículas resultam das variações de volume de materiais presentes na argamassa. As causas estão atreladas à presença de pedras de cal parcialmente extintas, matéria orgânica, e outras impurezas. 0 aparecimento de vesículas pode ser ocasionado devido a impurezas contidas nos agregados (Bauer et al., 2015). Essas impurezas, tal como aglomerados argilosos, pirita, mica, agregações ferruginosas e matéria orgânica, podem se expandir e formar produtos de oxidação que são as vesículas propriamente ditas.

\section{Metodologia}

\subsection{Perfil de degradação das fachadas revestidas de argamassa}

Embora os diversos defeitos apresentem diferentes causas, há uma ocorrência preferencial de defeitos em áreas específicas da fachada. Sendo assim Piazzarollo et al. (2019) optaram por identificar as zonas de fachada em que ocorrem mais defeitos e qual as áreas de preferência em que essas ocorrem. As zonas 
definidas se adequam a tipologia construtiva mais comum no Distrito Federal, capital do Brasil e contemplam seis zonas, conforme ilustrado na Figura 3.

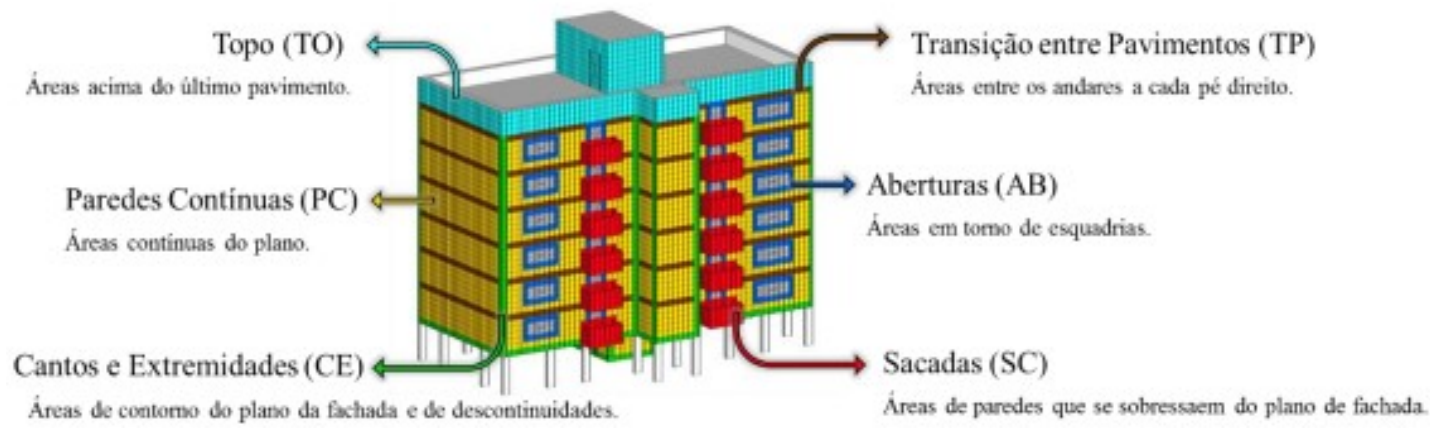

Figura 3 - Delimitação das Zonas Constituintes de Fachada (adaptado de Piazzarollo et al., 2019)

A definição das zonas constituintes permite realizar uma análise das particularidades de cada uma, estabelecendo conexão com os principais defeitos e as causas mais comuns. O Quadro 1 apresenta as causas e os principais defeitos que podem surgir nas zonas da fachada.

Quadro 1 - Principais causas dos defeitos nas zonas constituintes da fachada

\begin{tabular}{|c|c|c|}
\hline Zona & Defeitos & Causa \\
\hline \multirow{2}{*}{$\begin{array}{l}\text { Paredes Contínuas } \\
\text { (PC) }\end{array}$} & Descolamento & $\begin{array}{l}\text { Presença de áreas de grande extensão com restrições de } \\
\text { contorno, deformações e tensões consideráveis. A execução } \\
\text { inadequada pode fragilizar a resistência da argamassa sobre o } \\
\text { efeito de esforços. A argamassa quando muito rica ou em } \\
\text { camada espessa, sem chapisco, aplicada em superfície de base } \\
\text { muito lisa, é mais sensível a esforços. }\end{array}$ \\
\hline & Fissuração & $\begin{array}{l}\text { Comumente devido a cargas cíclicas, o revestimento está } \\
\text { submetido a cargas superiores a sua capacidade de resistência. } \\
\text { A retração da argamassa que pode ser causada por variações } \\
\text { de temperatura, reações químicas, carbonatação. Dessa forma } \\
\text { PC são propícias a fissuras. }\end{array}$ \\
\hline \multirow{4}{*}{$\begin{array}{l}\text { Aberturas } \\
\qquad \text { (AB) }\end{array}$} & Eflorescência & $\begin{array}{l}\text { Ocorre devido a presença de umidade, essa induz um fluxo de } \\
\text { água no substrato que pode conter impurezas. As parades } \\
\text { contínuas em restrições de seu contorno podem apresentar } \\
\text { pontos de acúmulo de água. }\end{array}$ \\
\hline & Descolamento & $\begin{array}{l}\text { As aberturas são zonas com concentração alta de esforços. } \\
\text { Sendo assim são suscetíveis a formação de fissuras, } \\
\text { principalmente nos perímetros dos vãos. Essas fissuras podem } \\
\text { evoluir e causar descolamentos. }\end{array}$ \\
\hline & Manchas de umidade & $\begin{array}{l}\text { Devido as fissuras que ocorrem nos cantos, pode-se formar } \\
\text { regiões que acumulam água e consequentemente causam } \\
\text { manchas. }\end{array}$ \\
\hline & Fissuração & $\begin{array}{l}\text { A fissuração ocorre quando a argamassa contrai ou aumenta } \\
\text { seu volume devido as variações de umidade, essa pode derivar } \\
\text { também da incidência de radiação que provoca reações } \\
\text { químicas, ou da incidência de esforços superiores a capacidade } \\
\text { resistiva da argamassa. As aberturas por conta de sua } \\
\text { geometria propiciam este fenômeno, é uma zona de acúmulo } \\
\text { de esforços. }\end{array}$ \\
\hline \multirow{2}{*}{$\begin{array}{l}\text { Topo } \\
\text { (TO) }\end{array}$} & Manchas de umidade & $\begin{array}{l}\text { O topo encontra-se sobre a ação direta da chuva, sendo assim } \\
\text { é propício ao surgimento de manchas de umidade. }\end{array}$ \\
\hline & Fissuração & $\begin{array}{l}\text { Essa zona é submetida a significante variação térmica e a } \\
\text { presença de umidade. Cita-se também a incompatibilidade de } \\
\text { deformação entre os elementos constituintes de fachada. }\end{array}$ \\
\hline
\end{tabular}




\begin{tabular}{|c|c|c|}
\hline \multirow{2}{*}{$\begin{array}{l}\text { Transição entre } \\
\text { Pavimentos } \\
\text { (TP) }\end{array}$} & Fissuração & $\begin{array}{l}\text { Nessa zona o dimensionamento inadequado ou a falta de } \\
\text { juntas de deformação impede a absorção adequada de } \\
\text { esforços. Fissuras então podem surgir como resultado de } \\
\text { esforços que ultrapassam a capacidade resistiva do } \\
\text { revestimento aplicado. }\end{array}$ \\
\hline & Descolamento & $\begin{array}{l}\text { Além das fissuras é possível o surgimento de descolamentos de } \\
\text { argamassa devido a elevada concentração de esforços. } \\
\text { Situação que tende a se agravar na ausência de juntas. }\end{array}$ \\
\hline \multirow{2}{*}{$\begin{array}{l}\text { Cantos e } \\
\text { Extremidades } \\
\text { (CE) }\end{array}$} & Fissuração & $\begin{array}{l}\text { Nessas zonas ocorre elevada concentração de esforços de } \\
\text { contração e retração, intensificadas pela ação da umidade e } \\
\text { temperatura. Assim, a fissuração é favorecida. }\end{array}$ \\
\hline & Descolamento & $\begin{array}{l}\text { Nessas zonas ocorre elevada concentração de esforços de } \\
\text { contração e retração, intensificadas pela ação da umidade e } \\
\text { temperatura. }\end{array}$ \\
\hline \multirow{4}{*}{$\begin{array}{l}\text { Sacadas } \\
\text { (SC) }\end{array}$} & Eflorescência & $\begin{array}{l}\text { As sacadas são zonas mais expostas a ação chuva e radiação, } \\
\text { favorecendo o surgimento de manchas. }\end{array}$ \\
\hline & Fissuração & $\begin{array}{l}\text { Nessa zona encontra-se um elemento em balanço no edifício, } \\
\text { concentrando tensões e deformações. Há também ação mais } \\
\text { intensa de chuva e radiação. }\end{array}$ \\
\hline & Descolamento & $\begin{array}{l}\text { Devido a fadiga, variações térmicas e solicitações de esforços, } \\
\text { as sacadas se encontram sujeitas a ocorrência de } \\
\text { descolamentos de argamassa. }\end{array}$ \\
\hline & Manchas de Umidade & $\begin{array}{l}\text { As sacadas podem apresentar regiões de acúmulo de água, } \\
\text { resultando em manchas de umidade. }\end{array}$ \\
\hline
\end{tabular}

\subsection{Matriz de correlação}

A relação das zonas com os defeitos podem ser obtidas pelo Índice de Relação (IR). Por meio de matrizes de correlação é possível calcular o IR (Equação 1), onde as linhas referem-se aos defeitos e as colunas às zonas de fachada, conforme ilustrado no Quadro 2. Conforme proposto por Silvestre e de Brito (2008), a matriz é preenchida com valores de 0,1 e 2, em que 0 significa que não há relação, 1 há uma relação indireta e 2 há uma relação direta do defeito com a zona.

Quadro 2 - Relação entre defeitos e zonas de fachada

\begin{tabular}{|c|c|c|c|c|c|c|}
\hline Defeitos & $\begin{array}{c}\text { Paredes } \\
\text { Contínuas }\end{array}$ & Aberturas & Sacadas & $\begin{array}{c}\text { Cantos e } \\
\text { Extremidades }\end{array}$ & $\begin{array}{c}\text { Transição } \\
\text { entre } \\
\text { Pavimentos }\end{array}$ & Topo \\
\hline Descolamento & 2 & 2 & 2 & 2 & 2 & 1 \\
\hline Eflorescência & 0 & 2 & 2 & 0 & 0 & 1 \\
\hline Fissuração & 2 & 2 & 2 & 2 & 2 & 2 \\
\hline Manchas de Umidade & 0 & 2 & 2 & 0 & 0 & 2 \\
\hline
\end{tabular}

$$
I R_{\text {Defeito }}=\frac{\sum_{j=1}^{N} P_{j}}{P_{\text {total }}}
$$

Onde $I R_{\text {defeito }}$ é $o$ indice de relação do defeito com as zonas, $N$ é a quantidade de zonas $(1=P C ; 2=A B ; 3=$ SC; 4 = CE; 5 = TP; 6 = TO), P é o peso atribuído a cada defeito relacionado à zona je $\mathrm{P}_{\text {Total }}$ é soma de todos os pesos atribuídos na matriz de correlação.

$$
I R_{\text {zona }}=\frac{\sum_{i=1}^{G} Z_{i}}{Z_{\text {total }}}
$$


Onde $I R_{\text {zona }}$ é o índice de relação da zonas com os defeitos, $G$ é a quantidade de defeitos $(1=$ Descolamento; 2 = Eflorescência; 3 = Fissuração; 4 = Manchas de umidade), $Z$ é o peso atribuído a cada zona i relacionado ao defeito e $Z_{\text {Total }}$ é soma de todos os pesos atribuídos na matriz de correlação.

\section{Resultados e discussões}

A análise das zonas em que surgem os defeitos relacionados às suas causas permitiu obter o Índice de Relação (IR) das zonas e dos defeitos. A Figura 4 mostra os resultados obtidos para $I R_{\text {defeitos. }}$.

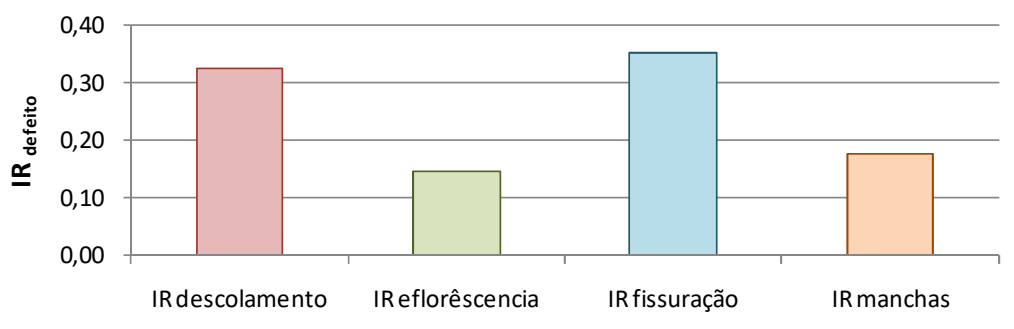

Figura 4 - Índice de Relação do defeito com as zonas

O maior valor obtido $(0,35)$ para o Índice de Relação dos defeitos refere-se à fissuração. Este fato indica que em geral todas as zonas das fachadas revestidas por revestimento em argamassa são frágeis quanto à ação de esforços concentrados. Conforme Fiorito (2010) e Uchôa (2015), as fissuras ocorrem devido a deformações induzidas, diretamente ou indiretamente, por esforços de tração. Esses esforços se acumulam em vários pontos ao longo de um edifício, especialmente naqueles onde a brusca alteração de geometria construtiva. A execução e/ou utilização de materiais inadequados e impuros reduz a capacidade de resistência do revestimento em argamassa, intensificando esse processo. Os defeitos de eflorescência apresentaram os menores valores $\left(\mathbb{R}_{\text {eflorescência }}=0,15\right)$. Possivelmente, este fato ocorreu devido ao número maior de condições necessárias para a sua ocorrência. O surgimento de eflorescência ocorre quando há a coexistência de três condições: presença de umidade, presença sais solúveis nos materiais e condições ambientais que permitem o fluxo de água. Desta forma, uma vez que algumas zonas tendem a apresentar menos umidade que outras, o Índice de Relação referente à eflorescência se torna menor quando se considera todas as zonas.

A Figura 5 ilustra os valores de IR para as zonas. Estes valores refletem à facilidade em que estas zonas podem se degradar devido ao surgimento dos defeitos.

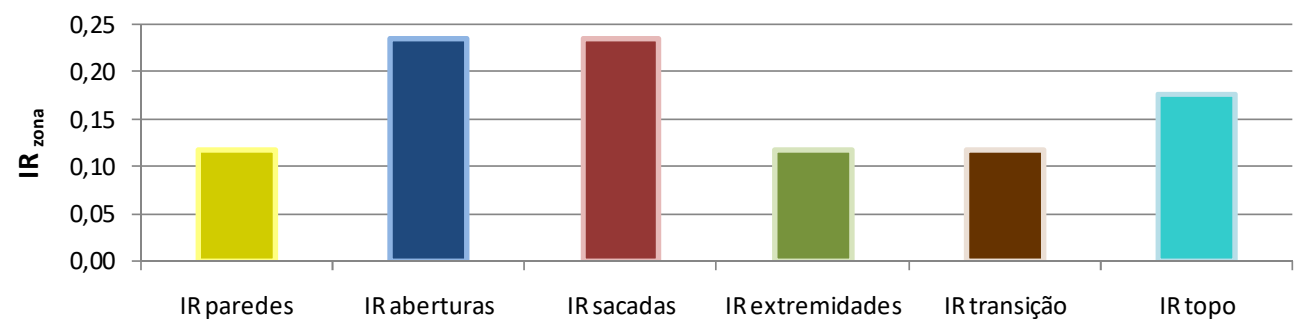

Figura 5 - Índice de Relação das zonas com os defeitos

Os valores mais elevados de $\mathbb{I R}_{\text {zona }}$ são iguais a 0,23 e referem-se às zonas de sacadas e aberturas. Estes valores estão associados às características e peculiaridades destas zonas. As zonas de sacadas apresentam condições de exposição desfavorável, devido ao ressalto do alinhamento da parede dos edifícios, permitindo a ação de chuva e radiação mais intensa que nas demais zonas e, consequentemente, o surgimento de defeitos oriundos da exposição às intempéries (Yang et al., 2015; Souza et al., 2019). Além disso, esta zona apresenta também uma incidência de cargas e esforços consideráveis. Quanto às zonas de aberturas, é comum o surgimento de fissuras nos cantos inferior devido á ausência de verga e contra-verga. 
Este defeito possibilita a infiltração de água e podem acarretar no surgimento de manchas e descolamento (Torres e Silva, 2015).

As zonas de paredes contínuas, transição entre pavimentos e cantos e extremidades apresentaram os menores valores, equivalente a 0,12. Conforme Silva (2014), nesta zona dificilmente os defeitos serão associados à presença de umidade, mas frequentemente é associado às restrições em seu contorno dificultando a dissipação ou acomodação das deformações, assim convergindo no surgimento de defeitos de fissuração e descolamento. A transição entre pavimentos é a zona que zona tende a apresentar uma variedade menor de defeitos correlacionada diretamente, quando comparada as zonas de sacada ou aberturas. Conforme Souza et al. (2019), a transição entre pavimentos é a zona que contempla elementos estruturais e tendem a apresentar um sistema mais rígido que as demais zonas. Na zona referente aos cantos e extremidades frequentemente ocorre o surgimento de defeitos devido a elevada concentração de esforços resultantes dos movimentos de dilatação ou retração (Bauer et al., 2015; Sousa et al., 2016). Sendo assim, esta zona não tende a apresentar defeitos associados à presença de umidade.

\section{Conclusões}

Esta pesquisa sintetiza os principais conceitos relativos aos defeitos em sistemas de revestimento em argamassa, relacionando-os com as zonas constituintes da fachada. Após apresentado os principais defeitos e as zonas constituintes da fachada de edifícios localizados no distrito Federal, foi possível observar uma correspondência entre as zonas constituintes e o surgimento de defeitos. Dentre os defeitos analisados, a fissuração apresenta a maioria das causas relacionadas a projeto e execução. A ação de agentes externos é determinante no surgimento de defeitos de manchas e descolamento. Desta forma, é importante enfatizar a necessidade de práticas construtivas executadas com os cuidados e atenção necessária.

\section{Agradecimentos}

Os autores agradecem o apoio da Universidade de Brasília e a disponibilização das informações fornecidas pelo grupo de pesquisa do programa de pós graduação em estruturas e construção civil da Universidade de Brasília que investiga degradação em fachadas.

\section{Referências Bibliográficas}

Alucci, M. P., Flauzino, W. D., \& Milano, S. (1988). Bolor em edifícios: causas e recomendações. Pini, IPTInstituto de Pesquisas Tecnológicas de São Paulo: São Paulo, 1, 565.

Amorim, C. N.; Flores, A. L. (2005) Edifícios residenciais das super quadras do Plano Piloto, Brasília: Aspectos de preservação e conforto ambiental. Encontro Nacional e Latino-Americano de Conforto no Ambiente Construído - ENCAC/ELACAC. Maceió, Brasil. pp. 37-46.

Barros, A. V. A., \& Moura, K. L. D. (2017). Desplacamento em revestimento cerâmico em fachada nos bairros do Farol e Ponta Verde na cidade de Maceió. Trabalho de conclusão de curso (Bacharelado Em Engenharia Civil) - Curso De Engenharia Civil. Centro Universitário Cesmac. Maceió, Brasil.

Bauer, E., Castro, E. K., Pavon, E., \& Oliveira, A. H. S. (2015). Criteria for application and identification of anomalies on the facades of buildings with the use of passive infrared thermography. In 1st Int. Symp. Build. Pathol., Porto, Portugal (Vol. 12).

Braga, D. K., \& Amorim, C. N. (2004). Conforto térmico em edifícios residenciais do Plano Piloto de Brasília. Conferência latino-americana de Construção Sustentável e Encontro Nacional de Tecnologia do Ambiente Construído - ENTAC. São Paulo, Brasil.

Fiorito, A. J. (2010). Manual de argamassas e revestimentos: estudos e procedimentos de execução. Vol 2. Ed. São Paulo. Pini. 
Flores-Colen, I., de Brito, J., \& Freitas, V. P. (2004). Methodology for vertical envelope design, inspection and maintenance. In 2 nd CIB Student Chapters International Symposium-Sustainability and Innovation in Construction and Real Estate, Tsinghua University, Pequim, China (pp. 269-278).

Hovde, P. J., \& Moser, K. (2004). Performance based methods for service life prediction. State of the art reports, CIB Report: Publication, 294.

Leal, U. (2002) Revestimento Mínimo. Téchne- Revista De Tecnologia E Negócios Da Construção. São Paulo, Ano 11, N.58.

Medeiros, J. S.; Sabbatini, F. H. (1999) Tecnologia e projeto de revestimentos cerâmicos de fachadas de edifícios. Boletim Técnico da Escola Politécnica da Universidade de São Paulo. São Paulo, Brasil.

Pereira, C., de Brito, J. \& Silvestre, J. (2020). Sistema global de inspecção, diagnóstico e reparação de edifícios: Homogeneização de matrizes de correlação. Encontro de Conservação e Reabilitação de Edifícios - ENCORE. Lisboa, Portugal.

Piazzarollo, C. B. ; Souza, J. S. ; Bauer, E. (2019). Análise das anomalias em sistemas de revestimento cerâmico nas diferentes zonas da fachada. Simpósio Brasileiro de Tecnologia das argamassas - SBTA, Goiânia, Brasil.

Santos, M. J. B. O. (2017) Catalogação de patologias em fachadas de edifícios residenciais de Brasília. Dissertação de Mestrado. Programa de Pós Graduação em Estruturas e Construção Civil. Universidade de Brasília. Brasília, Brasil.

Segat, G. T. (2005). Manifestações patológicas observadas em revestimentos de argamassa: estudo de caso em conjunto habitacional popular na cidade de Caxias do Sul (RS). Dissertação de Mestrado. Escola de Engenharia. Universidade Federal do Rio Grande do Sul. Porto Algre, Brasil.

Shohet, I. M., Rosenfeld, Y., Puterman, M., \& Gilboa, E. (1999). Deterioration patterns for maintenance management - A methodological approach. International Conference on Durability of Building Materials and Components - DBMC. pp. 1666-1678. Vancouver, Canadá.

Silva, M. N. B. (2014). Avaliação quantitativa da degradação e vida útil de revestimentos de fachada: aplicação ao caso de Brasília/DF. Tese de Doutorado. Programa de Pós Graduação em Estruturas e Construção Civil. Universidade de Brasília. Brasília, Brasil.

Silvestre, J. e de Brito, J. (2008). Inspecção e diagnóstico de revestimentos cerâmicos aderentes. Revista Engenharia Civil, Universidade do Minho, Portugal.

Sousa, H.; Sousa, R.; Silva, F. M.; Sousa, F. (2016) Fachada de edifícios.

Souza, J. S., Piazzarollo, C. B., \& Bauer, E. (2019) Degradação nas diferentes zonas de fachadas em sistemas de revestimento. Simpósio Brasileiro de Tecnologia das Argamassas - SBTA. Goiânia, Brasil.

Torres, A. S., \& Silva, J. (2015). Patologias nos sistemas construtivos das edificações do início do século XX no sul do Rio Grande do Sul-estudo de caso de residencia na cidade de Rio Grande/RS. REEC-Revista Eletrônica de Engenharia Civil, vol. 10. n. 2.

Uchôa, J. C B. (2015). Análise numérica e experimental da fadiga termomecânica em argamassas colantes no sistema de revestimento cerâmico. Tese de Doutorado. Programa de Pós Graduação em Estruturas e Construção Civil. Universidade de Brasília. Brasília, Brasil.

Uliana, J., Falcão, A., Soares, R., \& Vieira, G. (2014). Estudo da incidência de manifestações patológicas em fachadas de edifícios localizados em região litorânea. Congresso Brasileiro de Patologia das Construções - CONPAT. Foz do Iguaçu, Brasil.

Verçoza, E.J. (1991). Patologia Das Edificações. Porto Alegre: Sagra.

Yang, J., Wang, Z. H., \& Kaloush, K. E. (2015). Environmental impacts of reflective materials: Is high albedo a 'silver bullet'for mitigating urban heat island?. Renewable and Sustainable Energy Reviews, vol. 47, pp. 830-843. 